\title{
Influence of deposition conditions on structure parameters and mechanical properties of multi- element coatings based on niobium nitride
}

\author{
Vladimir Tabakov ${ }^{1}$, Aleksey Chikhranov ${ }^{1,2, *}$, and Yana Dolzhenko ${ }^{2}$ \\ ${ }^{1}$ Federal State Budgetary Educational Institution of Higher Education Ulyanovsk State Technical \\ University, Ulyanovsk, Russian Federation \\ ${ }^{2}$ Federal State Budgetary Educational Institution of Higher Education Ulyanovsk Institute of Civil \\ Aviation named after Chief Marshal of Aviation B.P. Bugaev, Ulyanovsk, Russian Federation
}

\begin{abstract}
The paper presents the results of studies of the influence of the deposition conditions, coatings NbTiZrN, NbTiAlN on structure parameters and mechanical properties. It is shown that the changes of these parameters depend on the composition of coatings. It was found that the condensation temperature affects the phase composition of the coating. Data obtained can be used when choosing functional layers of multielement coatings.
\end{abstract}

\section{Introduction}

Wear-resistant coatings boost the efficiency of cutting tools [1-5]. Multi-element coatings are increasingly applied [6-9]. To boost the efficiency of functional layers of multi-element coatings it is necessary to have data on the influence of various factors accompanying their deposition process on their mechanical properties.

Objective of this research is to study the influence of the composition and deposition conditions of coatings on their structural parameters and mechanical properties

\section{Methodology of Experiment}

Multi-element coatings based on niobium nitride NbTiZrN and NbTiAlN were studied. They were applied on carbide blades MK8 and plates of 20X13 and P6M5 steel using «Bulat-6» unit. Chemical composition of coatings was determined by the quantitative X-ray spectroscopic analysis method using the apparatus MAP-4 taking into consideration ZAFmodifications. Structural parameters of coatings (the lattice spacing $a$, the half-width of the $\mathrm{X}$-ray diffraction line $\beta_{004}$ ) and residual compressive stresses $\sigma_{0}$ were studied using the Xray diffraction meter «ДРОН-3М», sizes of coherent scattering regions (CSR) $D$ were calculated using the method described in the paper [10]. Micro-hardness $H_{M}$, elasticity modulus $E$ and stress intensity coefficient $K_{I C}$ of coatings were determined using methods

\footnotetext{
* Corresponding author: chihranov@mail.ru
} 
described in the paper [11]. Adhesion strength of coatings with the instrumental base was estimated by the stripping coefficient $K_{0}$ [12].

\section{Research Results and Discussion}

NbTiZrN coatings were applied using two cathodes of niobium and a composite cathode of titan with a zirconium insertion. Coating composition was changed by varying the area of zirconium insertions. When applying NbTiAlN coating, we used cathodes of niobium, alloy of niobium, titan and aluminum and alloy of titan and aluminum. Coating composition was changed by varying the layout diagram of the unit - the combination of cathodes used. Chemical composition of coatings is presented in Table 1.

Table 1. Chemical composition of coatings

\begin{tabular}{|c|c|c|c|c|}
\hline \multirow{2}{*}{ Coating } & \multicolumn{4}{|c|}{ Content of elements, \% at. } \\
\cline { 2 - 5 } & $\mathrm{Nb}$ & $\mathrm{Ti}$ & $\mathrm{Zr}$ & $\mathrm{Al}$ \\
\hline NbTiAlN (№ 1) & 67.20 & 32.60 & - & 0.20 \\
\hline NbTiAlN (№ 2) & 40.0 & 49.16 & - & 10.84 \\
\hline NbTiZrN (№ 1) & 65.70 & 33.50 & 0.80 & - \\
\hline NbTiZrN (№ 2) & 46.49 & 41.94 & 11.57 & - \\
\hline
\end{tabular}

It has been established that multi-element coatings NbTiZrN and NbTiAlN are singlephased ones. They have a tetragonal lattice with predominant texture (004) compared to nitride NbN having the hexagonal lattice $[13,14]$. As Table 2 shows, coatings NbTiZrN and NbTiAlN are characterized with higher parameter values of the lattice, smaller value of the X-ray line half-width and substantially smaller compression residual stresses (by 1,6...2,7 times smaller compared to $\mathrm{NbN}$ ), slight increase of CSR block sizes.

Table 2. Influence of the coating composition on structural parameters and residual stresses

\begin{tabular}{|c|l|c|c|c|c|c|}
\hline $\begin{array}{c}\text { Instrumental } \\
\text { base }\end{array}$ & \multicolumn{1}{|c|}{ Coating } & $a, \mathrm{~nm}$ & $c, \mathrm{~nm}$ & $D, \mathrm{~nm}$ & $\beta 004$, grad & $\sigma 0, \mathrm{MPa}$ \\
\hline \multirow{3}{*}{ 20X13 } & NbN & 0.2994 & 0.5594 & 9.24 & $1.13^{*}$ & $-2893 \pm 94$ \\
\cline { 2 - 7 } & NbTiZrN (№ 1) & 0.4415 & 0.8764 & 10.35 & 0.93 & $-2085 \pm 84$ \\
\cline { 2 - 7 } & NbTiAlN (№ 1) & 0.4417 & 0.8684 & 13.76 & 0.71 & $-1828 \pm 124$ \\
\hline \multirow{3}{*}{ P6M5 } & NbN & 0.3020 & 0.5751 & 8.66 & $1.20 *$ & $-4716 \pm 348$ \\
\cline { 2 - 7 } & NbTiZrN (№ 1) & 0.4470 & 0.8764 & 11.65 & 0.83 & $-2904 \pm 312$ \\
\cline { 2 - 7 } & NbTiAlN (№ 1) & 0.4394 & 0.8704 & 13.76 & 0.70 & $-1742 \pm 15$ \\
\hline \multicolumn{7}{|l}{ Note: * measured by peak (100) } \\
\hline
\end{tabular}

Study of mechanical properties (Table 3) showed that micro-hardness and elastic module of three-element coatings do slightly differ from niobium nitride. NbTiZrN coating is characterized with higher values of micro-hardness and elastic module. Stress-intensity factor of multi-element coatings is higher compared to $\mathrm{NbN}$ coating by $8.4 \ldots 23 \%$. This indicates higher crack resistance. Resistance to abrasive wear $H_{\mu} / E$ and plastic straining $H_{\mu}{ }^{3} / E^{2}$ of multi-element coatings and $\mathrm{NbN}$ differ slightly. Adhesion strength of multielement coatings is lower compared to $\mathrm{NbN}$. It is evidenced by higher values of the delamination coefficient.

Table 3. Mechanical properties of coatings (base - MK8)

\begin{tabular}{|c|c|c|c|c|c|c|}
\hline Coating & $H_{\mu}, \mathrm{GPa}$ & $K_{0}$ & $\begin{array}{c}K_{I C}, \\
\mathrm{MPa} \cdot \mathrm{m}^{1 / 2} / 2\end{array}$ & $E, \mathrm{GPa}$ & $H_{\mu} / E$ & $H_{\mu}{ }^{3} / E^{2}$ \\
\hline NbN & 29.8 & 0.12 & 9.78 & 467 & 0.064 & 0.121 \\
\hline NbTiAlN & 30.2 & 0.26 & 12.04 & 445 & 0.068 & 0.139 \\
\hline NbTiZrN & 32.6 & 0.19 & 10.60 & 575 & 0.057 & 0.105 \\
\hline
\end{tabular}


Change of the coating composition slightly influences its phase composition. For NbTiAlN coatings of various composition, the diffraction peak of $\mathrm{NbN}$ (004) of maximum intensity is observed almost at one and the same angle $2 \theta=41.4$ grad. For NbTiZrN coatings, reducing $\mathrm{Nb}$ and increasing $\mathrm{Ti}$ and $\mathrm{Zr}$ respectively lead to displacement of the diffraction peak of $\mathrm{NbN}(004)$ from the angle $2 \theta=41.2$ grad. to the angle $2 \theta=35.4$ grad.

Comparing of data, presented in Tables 2 and 3, shows that change of composition differently influences structural parameters of coatings. For NbTiZrN coatings, parameter values of the lattice, X-ray line half-width, CSR block sizes almost do not depend on the composition. At the same time, the value of compression residual stresses in coatings with the lower content of niobium is by 2.0...2.8 times higher.

Table 4. Structural parameters of coatings and residual stresses

\begin{tabular}{|c|c|c|c|c|c|c|}
\hline Coating & Base & $a, \mathrm{~nm}$ & $c, \mathrm{~nm}$ & $D, \mathrm{~nm}$ & $\beta_{004}$, grad & $\sigma_{0}, \mathrm{MPa}$ \\
\hline \multirow{2}{*}{ NbTiZrN } & $20 X 13$ & 0.4420 & 0.8678 & 11.75 & 0.81 & $-6212 \pm 235$ \\
\cline { 2 - 7 } & P6M5 & 0.4407 & 0.8747 & 12.39 & 0.77 & $-5860 \pm 191$ \\
\hline \multirow{2}{*}{ NbTiAlN } & $20 X 13$ & 0.4366 & 0.8744 & 5.73 & 1.66 & $-5950 \pm 47$ \\
\cline { 2 - 7 } & P6M5 & 0.4302 & 0.8647 & 5.76 & 1.65 & $-4753 \pm 269$ \\
\hline Note: Data in the Table are for NbTiZrN (№2) and NbTiAlN (№2) coatings \\
\hline
\end{tabular}

Compared to NbTiZrN coating, change of NbTiAlN coating composition to a far greater degree influences structural parameters. Coatings with the lower content of niobium (NbTiAlN №2 coating) have higher values of the X-ray line half-width. This suggests the higher lattice deformation. Respectively, these coatings are characterized with lower CSR block sizes. Level of compression residual stresses in these coatings is by 2.7...3.2 times higher compared to NbTiAIN № 1 coatings.

Influence of the condensation temperature on the chemical composition of coatings is presented in Table 5. It has been established that change of the condensation temperature slightly influences the ration of deposited elements in the coating. At the same time, if the condensation temperature in NbTiAIN coating is higher, the aluminum composition will be slightly increased provided that the titan composition is decreased.

Table 5. Influence of the condensation temperature on the chemical composition of coatings

\begin{tabular}{|l|c|c|c|c|}
\hline \multirow{2}{*}{ Coating } & \multicolumn{4}{|c|}{ Content of elements, \% at. } \\
\cline { 2 - 5 } & $\mathrm{Nb}$ & $\mathrm{Ti}$ & $\mathrm{Zr}$ & $\mathrm{Al}$ \\
\hline NbTiAlN $^{*}$ & 68.17 & 27.23 & - & 4.60 \\
\hline NbTiAlN** $^{*}$ & 66.91 & 27.96 & - & 5.13 \\
\hline NbTiZrN $^{*}$ & 46.56 & 41.69 & 11.75 & - \\
\hline NbTiZrN** & 46.49 & 41.94 & 11.57 & - \\
\hline Note: $*$, ** at the temperature $300^{\circ} \mathrm{C}$ and $600^{\circ} \mathrm{C}$, respectively \\
\hline
\end{tabular}

Tables 6 and 7 show data on the influence of the condensation temperature on the phase composition of coatings. Figures 1 and 2 show diffractograms of NbTiZrN coating at different condensation temperatures.

It has been established that the condensation temperature has a great influence on the phase composition of the coating. When comparing data showed in Tables 6 and 7, it turns out that for NbTiZrN coating, obtained at the temperature $300{ }^{\circ} \mathrm{C}$, in the diffractogram (Fig. 1 , a) the diffraction peak of the highest intensity which is identified as $\mathrm{NbN}$ (112), common to the tetragonal structure, appears at the angle $2 \theta=35.4$ grad. In the diffractogram of the coating, obtained at the temperature $600{ }^{\circ} \mathrm{C}$ (Fig. 1, b), the additional diffraction peak appears at the angle $2 \theta=41$ grad. This fact is also common to the tetragonal structure and identified as NbN (200). Similar regularities of influence of the condensation temperature on the phase composition were also obtained for NbTiAlN coatings. 
Table 6. Phase analysis of NbTiZrN coating $\left(300{ }^{\circ} \mathrm{C}\right)$

\begin{tabular}{|c|c|c|c|c|c|c|c|c|}
\hline $\begin{array}{c}\text { Seq. } \\
\text { № }\end{array}$ & $\begin{array}{c}\text { Diffraction } \\
\text { angle 2 } \theta, \\
\text { grad }\end{array}$ & $\begin{array}{c}\text { Interplane } \\
\text { distance } \\
d_{\text {exp }, \mathrm{nm}}\end{array}$ & $\begin{array}{c}\text { Relative } \\
\text { intensity }\end{array}$ & $H K L$ & $\begin{array}{c}\text { Interplane } \\
\text { distance } \\
d_{\text {tabl, } \mathrm{nm}}\end{array}$ & $\begin{array}{c}\text { Coating } \\
\text { phases }\end{array}$ & $\begin{array}{c}\text { Base } \\
\text { phases }\end{array}$ & $\begin{array}{c}\text { Coating } \\
\text { structure }\end{array}$ \\
\hline 1 & 31.6 & 0.2831 & 0.36 & 002 & 0.2768 & $\mathrm{NbN}$ & & hexagonal \\
\hline 2 & 34.4 & 0.2607 & 1.00 & 100 & 0.2570 & $\mathrm{NbN}$ & & hexagonal \\
\hline 3 & 35.4 & 0.2536 & 1.00 & 112 & 0.2524 & $\mathrm{NbN}$ & & tetragonal \\
\hline 4 & 41.6 & 0.2171 & 0.02 & 004 & 0.2171 & $\mathrm{NbN}$ & & hexagonal \\
\hline 5 & 44.7 & 0.2027 & 1.00 & 110 & 0.2010 & & $\alpha-\mathrm{Fe}$ & \\
\hline 6 & 61.5 & 0.1507 & 0.30 & 110 & 0.1484 & $\mathrm{NbN}$ & & hexagonal \\
\hline 7 & 65.0 & 0.1435 & 0.49 & 200 & 0.1428 & & $\alpha-\mathrm{Fe}$ & \\
\hline 8 & 71.5 & 0.1320 & 0.05 & 116 & 0.1311 & $\mathrm{NbN}$ & & tetragonal \\
\hline
\end{tabular}
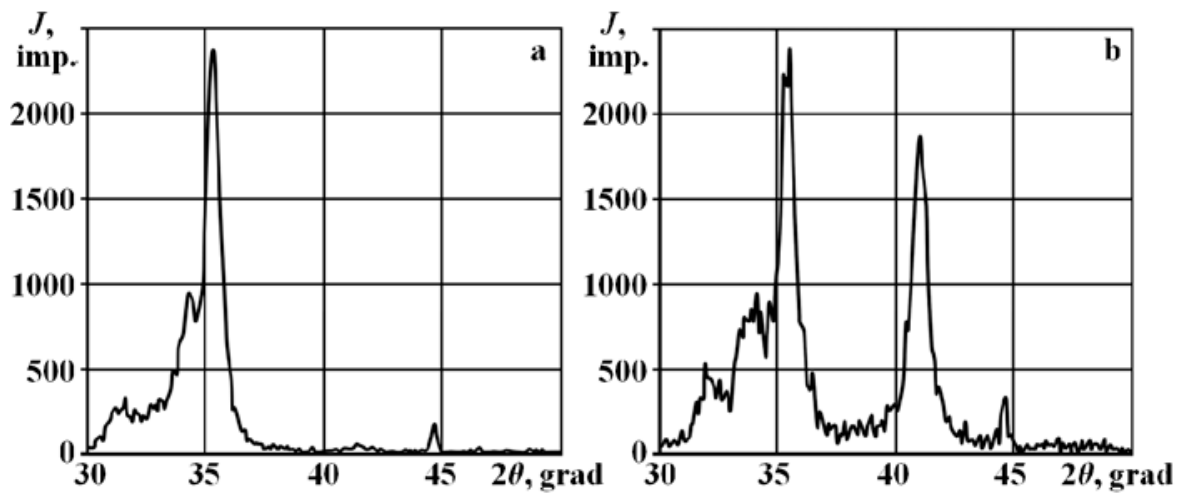

Fig. 1. Fragments of diffractograms of NbTiZrN coatings deposited at the temperature: $300{ }^{\circ} \mathrm{C}$ (a) and $600{ }^{\circ} \mathrm{C}(\mathrm{b})$

Table 7. Phase analysis of NbTiZrN coating $\left(600^{\circ} \mathrm{C}\right)$

\begin{tabular}{|c|c|c|c|c|c|c|c|c|}
\hline $\begin{array}{c}\text { Seq. } \\
\text { № }\end{array}$ & $\begin{array}{c}\text { Diffraction } \\
\text { angle 2 } \theta, \\
\text { grad }\end{array}$ & $\begin{array}{c}\text { Interplane } \\
\text { distance } \\
d_{\text {exp }}, \mathrm{nm}\end{array}$ & $\begin{array}{c}\text { Relative } \\
\text { intensity }\end{array}$ & $H K L$ & $\begin{array}{c}\text { Interplane } \\
\text { distance } \\
d_{\text {tabl, } \mathrm{nm}}\end{array}$ & $\begin{array}{c}\text { Coating } \\
\text { phases }\end{array}$ & $\begin{array}{c}\text { Base } \\
\text { phases }\end{array}$ & $\begin{array}{c}\text { Coating } \\
\text { structure }\end{array}$ \\
\hline 1 & 31.9 & 0.2805 & 0.55 & 002 & 0.2768 & $\mathrm{NbN}$ & & hexagonal \\
\hline 2 & 34.1 & 0.2629 & 1.0 & 100 & 0.2570 & $\mathrm{NbN}$ & & hexagonal \\
\hline 3 & 35.5 & 0.2529 & 1.0 & 112 & 0.2524 & $\mathrm{NbN}$ & & tetragonal \\
\hline 4 & 41.0 & 0.2201 & 0.78 & 200 & 0.2193 & $\mathrm{NbN}$ & & tetragonal \\
\hline 5 & 44.7 & 0.2027 & 1.0 & 110 & 0.2010 & & $\alpha-\mathrm{Fe}$ & \\
\hline 6 & 59.5 & 0.1554 & 0.08 & 220 & 0.1551 & $\mathrm{NbN}$ & & tetragonal \\
\hline 7 & 61.5 & 0.1508 & 0.33 & 110 & 0.1484 & $\mathrm{NbN}$ & & hexagonal \\
\hline 8 & 64.9 & 0.1437 & 0.42 & 200 & 0.1428 & & $\alpha$-Fe & \\
\hline 9 & 67.3 & 0.1391 & 0.19 & 004 & 0.1384 & $\mathrm{NbN}$ & & hexagonal \\
\hline 10 & 71.5 & 0.1320 & 0.19 & 116 & 0.1311 & $\mathrm{NbN}$ & & tetragonal \\
\hline 11 & 75.0 & 0.1266 & 0.13 & 224 & 0.1262 & $\mathrm{NbN}$ & & tetragonal \\
\hline
\end{tabular}

Influence of the condensation temperature on structural parameters and mechanical properties of coatings is shown in Tables 8 and 9 and in Fig. 2-4. It has been established that decreasing of the condensation temperature from $600{ }^{\circ} \mathrm{C}$ to $300{ }^{\circ} \mathrm{C}$ changes structural parameters and the value of compression residual stresses. The $\mathrm{X}$-ray line half-width is increased (by 11\%...64\%). CSR block sizes are decreased (by 1.2...1.6 times). Compression residual stresses are increased (by 1.1...1.4 times). Maximum change of abovementioned parameters is common to NbTiAlN coatings. 
Table 8. Influence of the condensation temperature on structural parameters of coatings

\begin{tabular}{|c|c|c|c|c|c|c|}
\hline Base & Coating & $a, \mathrm{~nm}$ & $c, \mathrm{~nm}$ & $\beta_{112}$, grad & $D, \mathrm{~nm}$ & $\sigma_{0}, \mathrm{MPa}$ \\
\hline \multirow{2}{*}{$20 \times 13$} & \multirow{2}{*}{ NbTiZrN } & $\underline{0,4417}$ & $\underline{0,8684}$ & $\underline{0,81}$ & 11.7 & $-6555 \pm 317$ \\
\hline & & 0,4403 & $\overline{0,8671}$ & $\overline{0,73}$ & 13,04 & $-5147 \pm 801$ \\
\hline \multirow{2}{*}{ P6M5 } & \multirow{2}{*}{ NbTiZrN } & $\underline{0,4362}$ & $\underline{0,8983}$ & $\underline{0,79}$ & $\underline{12,03}$ & $-5211 \pm 589$ \\
\hline & & 0,4403 & $\overline{0,8741}$ & 0,7 & $\overline{13,71}$ & $-4980 \pm 574$ \\
\hline \multirow{2}{*}{$20 \times 13$} & \multirow{2}{*}{ NbTiAlN } & $\underline{0,4417}$ & $\underline{0,884}$ & 1,02 & $\underline{9,41}$ & $-5962 \pm 516$ \\
\hline & & 0,4382 & 0,8680 & 0,84 & 11,58 & $-5249 \pm 330$ \\
\hline \multirow{2}{*}{ P6M5 } & \multirow{2}{*}{ NbTiAlN } & $\underline{0,4372}$ & $\underline{0,8791}$ & 1,19 & 7,98 & $-5273 \pm 290$ \\
\hline & & 0,4382 & 0,8543 & 0,73 & $\overline{13,4}$ & $-3834 \pm 548$ \\
\hline
\end{tabular}

Table 9. Influence of the condensation temperature on mechanical properties of coatings

\begin{tabular}{|c|c|c|c|c|}
\hline Coating & $\begin{array}{c}\text { Condensation } \\
\text { temperature } T_{k},{ }^{\circ} \mathrm{C}\end{array}$ & $E, \mathrm{GPa}$ & $H_{\mu} / E$ & $H_{\mu}{ }^{3} / E^{2}$ \\
\hline NbN & - & 467 & 0.064 & 0.121 \\
\hline NbTiAlN & 300 & 455 & 0.071 & 0.160 \\
\hline NbTiAlN & 600 & 426 & 0.072 & 0.158 \\
\hline NbTiZrN & 300 & 496 & 0.066 & 0.145 \\
\hline NbTiZrN & 600 & 474 & 0.067 & 0.144 \\
\hline
\end{tabular}

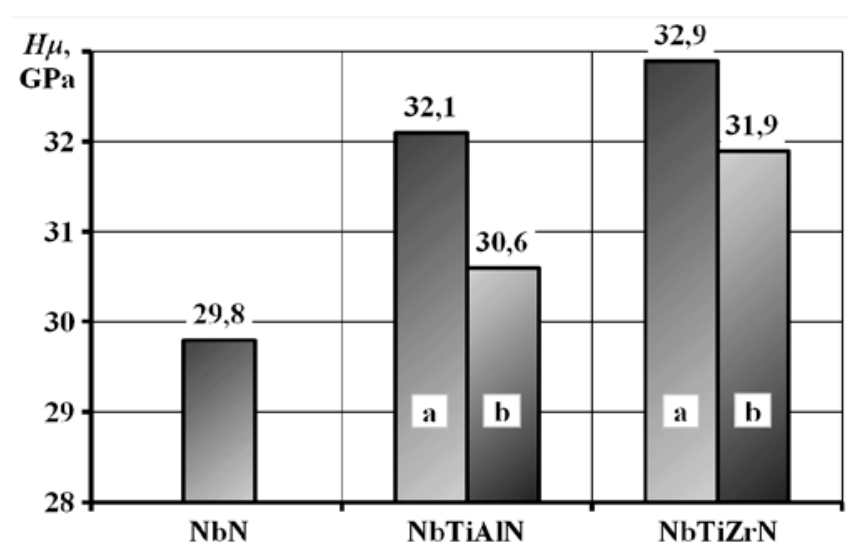

Fig. 2. Influence of the condensation temperature on the micro-hardness of wear-resistant coatings (condensation temperature: $\mathrm{a}-300^{\circ} \mathrm{C}, \mathrm{b}-600^{\circ} \mathrm{C}$ )

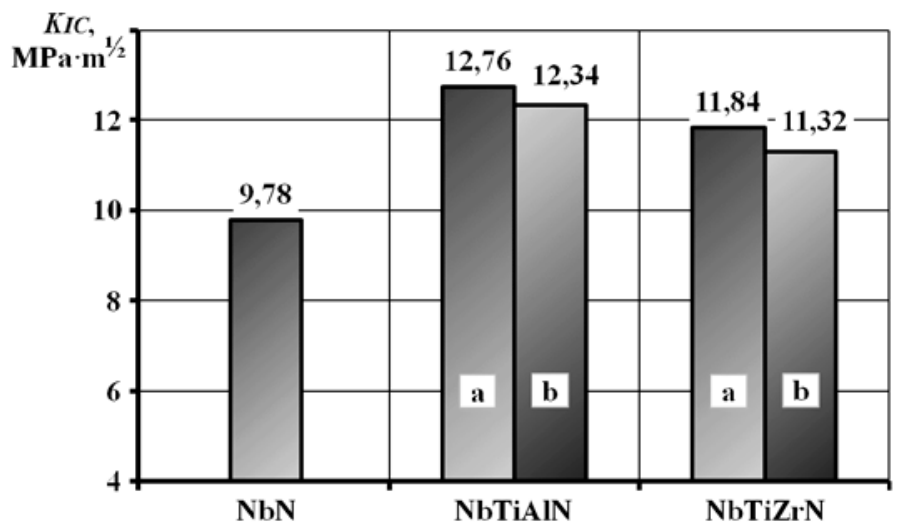

Fig. 3. Influence of the condensation temperature on the stress-intensity factor of coatings (condensation temperature: $\mathrm{a}-300{ }^{\circ} \mathrm{C}, \mathrm{b}-600^{\circ} \mathrm{C}$ ) 


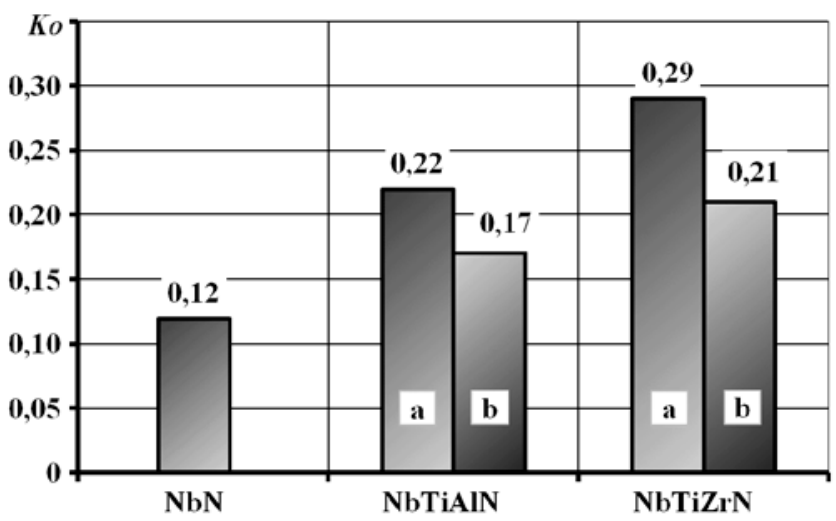

Fig. 4. Influence of the condensation temperature on the delamination coefficient of coatings (condensation temperature: $\mathrm{a}-300{ }^{\circ} \mathrm{C}, \mathrm{b}-600{ }^{\circ} \mathrm{C}$ )

Decrease of the condensation temperature leads to increase of mechanical properties of coatings. Coatings obtained at the low condensation temperature are characterized with higher values of the micro-hardness, elastic module, stress-intensity factor provided that the adhesion strength is decreased. Condensation temperature has the maximum influence on the adhesion strength. Delamination coefficient, characterizing the adhesion strength, of coatings obtained at the high temperature, is lower by 1.3...1.4 times. This fact suggests that their adhesion strength is higher. Results obtained are well within data of works [15, $16]$.

\section{Conclusion}

It has been established that deposition conditions of coatings based on niobium nitride influence the phase composition, structural parameters, residual stresses and mechanical properties. It is testified that changes of parameters mentioned above depend on the coating composition. Data obtained can be used when choosing functional layers of multi-element coatings.

This paper is drawn up with the aid of the grant from the Russian foundation for basic research (RFBR) - the project № 18-48-730011

\section{References}

1. B.Ya. Mokritskiy, STIN, 11, 11-15, (2010)

2. A.S. Vereshchaka, Efficiency of Cutters with Wear-resistant Coatings, (Rabotosposobnost rezhushchego instrumenta s iznosostoykimi pokrytiyami), Mashinostroyeniye, (1993)

3. V.M. Beresnev, O.V. Sobol, S.S. Grankin, U.S. Nemchenko, V.Yu. Novikov, O.V. Bondar, E.O. Belovol, O.V. Maksakova, D.K. Eskermesov, Physics and chemistry of the material processing, 4, 50-58, (2015)

4. M.A. Volosova, V.D. Gurin, Journal of Friction and Wear, 34 (3), 183-189, (2013)

5. I.V. Blinkov, O.A. Volkhonskii, V.N. Anikin et al, Protection of Metals and Physical Chemistry of Surfaces, 48 (6), 649-655, (2012)

6. S.N. Grigoriev, A.A. Vereschaka, A.S. Vereschaka, A.A. Kutin, Procedia CIRP, 1, 318-323 (2012) 
7. H. Cicek, O. Baran, A. Keles, Y. Totik, I. Efeoglu, Surf. Coat. Technol., 332, 296-303, (2017). https://doi.org/10.1016/j.surfcoat.2017.06.078

8. V.N. Gadalov, V.G. Salnikov, D.N. Romanenko, I.V. Shirin, Mechanical Engineering Technology, (Tekhnologiya mashinostroyeniya), 7, 26-28, (2011)

9. M. E. Maxims, Bulletin of the Moscow State Technical University MAMI, 4 (22), Vol. 2, 27-34, (2014)

10. S.S. Gorelik, L.N. Rastorguyev, Yu.A. Skakov, X-ray Structure and Electron-Optical Analysis of Metals (Rentgenostrukturny i elektronnooptichesky analiz metallov), Metallurgizdat, (1970)

11. V.P. Tabakov, A.V. Chihranov, Bulletin of Samara RAS Research Center, 12 (4), 292-297, (2010)

12. A.A. Andreev, S.N. Grigor'ev, Russian Engineering Research, 26 (2), 44-49, (2006)

13. V.I. Ivashchenko, P.L. Scrinskiy, O.S. Litvin, V.M. Rogoz, O.V. Sobol, A.P. Kuzmenko, H. Komsta and C. Karvat, ACTA PHYSICA POLONICA A, 5 (128), $950-$ 952, (2015)

14. V.P. Tabakov, A.V. Chikhranov, Russian Engineering Research, 38 (2), 105-109, (2018)

15. V.P. Tabakov. Formation of wear-resistant ion-plasma coatings of cutting tools, (Formirovanie iznosostojkih ionno-plazmennyh pokrytij rezhushchego instrumenta), Mashinostroenie, (2008)

16. V.P. Tabakov, L.V. Khudobin Hardening technologies and coatings 9, 414-416, (2018) 